\title{
KARAKTERISTIK DAN MOTIVASI BERWISATA KELOMPOK LANJUT USIA DI KOTA YOGYAKARTA
}

\author{
Dyah Widiyastuti \\ Departemen Geografi Pembangunan, Fakultas Geografi - Universitas Gadjah Mada \\ dwidiyastuti@ugm.ac.id
}

\begin{abstract}
The increasing group of elderly in some countries are very likely to turn into a new market segment for the tourism industry. To be able to capture the market opportunities of the elderly, tourism destinations need to be developed to meet the specific needs of this group. This study aims to assess the potential of tourism in Yogyakarta for elderly travelers, as well as to identify the barriers they faced in conducting their tourism activities.

This study used a qualitative approach through interviews with elderly travelers in 4 (four) major tourist destinations in the city of Yogyakarta which were: Gembira Loka Zoo, Vredeburg, Taman Pintar and Kraton Complex. Secondary data obtained from researches and data related to other tourism.

The results of this study were: The group of elderly people who visited tourist destinations where research were conducted mostly belong to group age of 60-65 years followed by the age group over 65 years and the age of 55-65 years. Elderly tourists did more passive activities than active, that were sitting, reading, sight-seeing, eating and chatting. While active activities performed by elderly travelers were walking, took photos and cared for grandchildren. Passive and active activities undertaken were determined by the presence of supporting facilities in the tourist attraction. Desire to travel of elderly differ with tourists in general. They were more driven by the desire to get together with other people, either with family or friends of their community. Therefore motivations that encouraged the elderly to travel were closely to the social motivation, impersonal, and physical motivations.
\end{abstract}

Keywords:

elderly, motivation, tourism

\section{Intisari}

Semakin bertambahnya golongan usia lanjut di beberapa negara menjadi segmen pasar baru bagi industri pariwisata. Untuk dapat menangkap peluang pasar lanjut usia tersebut, destinasi pariwisata perlu dikembangkan untuk memenuhi kebutuhan khusus golongan ini. Penelitian ini bertujuan untuk mengkaji potensi pariwisata di Daerah Istimewa Yogyakarta bagi wisatawan lanjut usia, sekaligus untuk mengidentifikasi hambatan yang mereka hadapi dalam melakukan kegiatan wisata. 
Penelitian ini menggunakan metode pendekatan kualitatif melalui interview dengan wisatawan lanjut usia yang berada di 4 (empat) destinasi wisata utama di Kota Yogyakarta yakni Kebun Binatang Gembira Loka, Taman Sari, Benteng Vredeburg, Taman Pintar dan Kompleks Kraton. Data sekunder didapatkan dari penelitian terkait maupun data kepariwisataan lain.

Hasil dari penelitian ini adalah: Kelompok lanjut usia yang mengunjungi ODTW yang menjadi lokasi penelitian sebagian besar berusia 60-65 tahun diikuti kelompok usia diatas 65 tahun dan usia 55-65 tahun. Keinginan berwisata kaum lanjut usia berbeda dengan wisatawan pada umumnya. Wisatawan lansia lebih banyak melakukan kegiatan wisata pasif (passive activities) yakni duduk, membaca, melihat-lihat, makan dan ngobrol. Sementara kegiatan aktif yang dilakukan oleh wisatawan lansia adalah jalan, mengambil foto dan mengasuh cucu. Aktivitas pasif dan aktif yang dilakukan wisatawan tersebut juga ditentukan oleh ada atau tidaknya fasilitas yang mendukung di obyek wisata yang dikunjungi. Keinginan berwisata mereka lebih didorong dengan keinginan untuk berkumpul bersama orang lain, baik bersama keluarga maupun teman-teman komunitas. motivasi yang mendorong lansia untuk berwisata lebih kepada motivasi sosial, impersonal, dan motivasi fisik.

Kata kunci:

lansia, motivasi, wisata

\section{PENDAHULUAN}

Kecenderungan perkembangan kepariwisataan dunia dari tahun ke tahun menunjukkan perkembangan yang sangat pesat. Hal ini disebabkan antara lain, oleh perubahan struktur sosial ekonomi negara di dunia dan tingkat pendapatan masyarakat yang semakin meningkat. Selain itu, kepariwisataan telah berkembang menjadi suatu fenomena global menjadi kebutuhan dasar serta menjadi bagian dari hak asasi manusia yang harus dihormati dan dilindungi. Pemerintah dan Pemerintah Daerah, dunia usaha pariwisata, dan masyarakat berkewajiban untuk dapat menjamin agar berwisata sebagai hak setiap orang dapat ditegakkan sehingga mendukung tercapainya peningkatan harkat dan martabat manusia, peningkatan kesejahteraan, serta persahabatan antar bangsa dalam rangka mewujudkan perdamaian dunia. Dalam rangka menghadapi perubahan global dan penguatan hak pribadi masyarakat untuk menikmati waktu luang dengan berwisata, perlu dilakukan pembangunan kepariwisataan yang bertumpu pada keanekaragaman, keunikan dan kekhasan bangsa dengan menempatkan hak setiap manusia untuk berwisata, tidak terkecuali kelompok masyarakat berkemampuan khusus yang didalamnya termasuk kelompok usia lanjut dan anak-anak.

Fenomena yang melatar belakangi penelitian ini adalah tingginya pertumbuhan penduduk golongan lanjut usia (lansia) di seluruh dunia. Seseorang disebut lanjut usia jika telah berusia 55 tahun atau lebih. Tingginya pertumbuhan tersebut telah dan akan menjadi segmen pasar baru bagi industri pariwisata. Profil wisatawan mancanegara lanjut usia telah menarik bagi industri pariwisata pada dua hal yakni daya beli yang tinggi dan waktu luang cukup panjang karena pada umumnya mereka telah menjalani masa pensiun. Namun, harus disadari bahwa kaum lanjut usia juga memiliki motivasi yang tidak sama dengan kelompok wisatawan usia lainnya. Hal ini lebih terkait dengan adanya kemunduran kemam-puan fisik dan psikologis seiring bertambahnya usia sehingga pemilihan jenis aktivitas disesuaikan dengan umur dan kemampuan fisik mereka.

Daerah Istimewa Yogyakarta termasuk propinsi berpenduduk struktur tua, karena persentase penduduk lanjut usia telah mencapai di atas $7 \%$ dari total penduduk. Hasil sensus penduduk tahun 2016 menunjukkan bahwa 
Propinsi DIY termasuk wilayah dengan jumlah penduduk lanjut usia terbanyak di Indonesia, yang mencapai 554.400 jiwa atau 15,28 persen dari total penduduk (BPS 2016). Struktur ageing population merupakan cerminan dari semakin tingginya rata-rata Usia Harapan Hidup (UHH) penduduk DIY. Usia harapan hidup masyarakat DIY berkisar 74 melebihi usia harapan hidup nasional berkisar 70 tahun (Pusdatin 2015). Tingginya UHH merupakan salah satu indikator keberhasilan pencapaian pembangunan baik di DIY maupun di tingkat nasional terutama di bidang kesehatan. Keadaan ini berkaitan dengan adanya perbaikan kualitas kesehatan dan kondisi sosial ekonomi masyarakat. Struktur penduduk yang menua tersebut, selain merupakan salah satu indikator keberhasilan pencapaian pembangunan manusia secara nasional, sekaligus juga merupakan tantangan dalam pembangunan.

Tingginya jumlah manusia lanjut usia menjadi peluang baru dalam pengembangan kepariwisataan. Sehingga pembangunan kepariwisataan untuk kelompok lansia menjadi suatu hal yang berpeluang menjadi sektor unggulan kepariwisataan di Yogyakarta. Adanya kebutuhan wisata untuk kaum lanjut usia selama ini kurang begitu diperhitungkan, padahal kelompok ini merupakan pasar yang sangat potensial bagi kepariwisataan di Yogyakarta. Pada kenyataannya, kebutuhan wisata bagi lansia di Yogyakarta belum terakomodasi secara optimal. Hal ini dapat dilihat dari sisi penyediaan sarana dan prasarana wilayah yang belum mendukung aktivitas lansia secara mandiri. Destinasi pariwisata di Yogyakarta untuk dapat menangkap peluang pasar lanjut usia tersebut, destinasi pariwisata perlu dikembangkan untuk memenuhi kebutuhan khusus golongan ini. Banyak hal yang mesti dipersiapkan guna menyediakan fasilitas khusus tersebut, terutama terkait standar pelayanan wisata seperti sarana dan prasarana infrastruktur, serta sumber daya manusia.

\section{\begin{tabular}{l|l} 
JNP & ${ }^{84}$
\end{tabular}

\section{TINJAUAN PUSTAKA}

\section{Pengertian Lanjut Usia}

Lansia merupakan kelompok umur pada manusia yang telah memasuki tahapan akhir dari fase kehidupannya. Kelompok yang dikategorikan lansia ini akan terjadi suatu proses yang disebut Aging Process atau proses penuaan sehingga rentan terhadap bermacam masalah kesehatan, dalam arti menurunnya daya tahan fisik yang ditandai dengan semakin rentannya terhadap serangan berbagai penyakit yang dapat menyebabkan kematian (BKKBN 2013). Undang Undang No. 13 Tahun 1998 mendefinisikan lansia adalah seseorang yang karena usianya mengalami perubahan biologik, fisik, kejiwaan dan sosial. Perubahan ini akan memberikan pengaruh pada aspek kehidupan termasuk kesehatannya.

Definisi tentang lanjut usia memang masih menjadi perdebatan dari beberapa kalangan di masyarakat khususnya yang berhubungan dengan umur seseorang yang disebut lanjut usia. Batasan usia lansia yang dimulai dari usia 60 tahun dikemukakan oleh World Health Organisation (WHO) dan Badan Koordinasi keluarga Berencana Nasional (BKKBN). Berbagai definisi diatas dapat disimpulkan bahwa lansia adalah seseorang yang telah mencapai usia 60 tahun atau lebih, dimana telah terjadi perubahan biologik, fisik dan mental dan rentan terjadi berbagai penyakit. Definisi oleh World Tourism Organisation (2005) dalam Hsu et.al. (2007) menjelaskan bahwa wisatawan lansia merupakan wisatawan yang telah berumur 55 tahun atau lebih. Pemerintah Indonesia juga mendifinisikan hal yang sama bahwa wisatawan mancanegara lanjut usia adalah wisatawan warga negara asing yang mempunyai usia sekurang-kurangnya 55 tahun. Pendefinisian tersebut ditetapkan pada Keputusan Presiden Republik Indonesia Nomor 31 Tahun 1998.

Terdapat beberapa perbedaan terkait ketetapan seseorang dianggap lanjut usia karena setiap negara memiliki kriteria yang berbeda. 
Menurut WHO (2007), klasifikasi lansia berdasarkan umurnya yaitu usia pertengahan (middle age) 45-59 tahun, lansia (elderly) 60-74 tahun, lansia tua (old) 75-90 tahun dan lansia sangat tua (very old) di atas 90 tahun. Berbeda dengan WHO, menurut Departemen Kesehatan RI (2006) pengelompokkan lansia menjadi : a) Virilitas (prasenium) yaitu masa persiapan usia lanjut yang menampakkan kematangan jiwa (usia 55-59 tahun), (b) Usia lanjut dini (senescen) yaitu kelompok yang mulai memasuki masa usia lanjut dini (usia 60-64 tahun) dan (c) Lansia berisiko tinggi untuk menderita berbagai penyakit degeneratif (usia $>65$ tahun).

Pada penelitian ini, dengan mengambil berbagai definisi diatas dapat disimpulkan bahwa lansia adalah seseorang yang telah mencapai usia 55 tahun atau lebih, dimana telah terjadi perubahan biologik, fisik dan mental dan rentan terjadi berbagai penyakit. Individu lanjut usia mengacu produktivitas seseorang dalam dunia kerja dan didasarkan pada umur kronologis seseorang, yakni yang mempunyai usia sekurang-kurangnya 55 tahun. Batas usia tersebut telah digunakan oleh institusi penyedia kerja untuk membatasi usia karyawannya, dimana usia pensiun dari dunia kerja formal dimulai di usia 55 tahun.

\section{Motivasi Berwisata}

Motivasiberwisataadalahsebuahpernyataan yang menunjukkan adanya suatu kondisi dimana seseorang terdorong untuk melakukan suatu aktivitas tertentu yang akan memberikan kepuasan bagi pelakunya (Esichaikul, 2012). Motivasi berwisata berhubungan dengan alasan mengapa manusia melakukan kegiatan wisata (Hsu et al., 2007). Motivasi seseorang untuk melakukan kegiatan wisata beragam mulai dari untuk sekedar menghilangkan stres akibat rutinitas, relaksasi, hingga untuk melakukan interaksi sosial dengan orang lain, sehingga bisa dikelompokkan menjadi motivasi internal dan eksternal. Lebih lanjut dikatakan bahwa motivasi merupakan hal yang sangat mendasar dalam studi tentang wisatawan dan pariwisata karena motivasi merupakan penggerak dari proses perjalanan wisata.

Ada beberapa teori tentang motivasi, namun teori motivasi yang paling mendasar adalah Teori Kebutuhan yang dicetuskan oleh Abraham Maslow dalam Hall \& Page (2002). Teori Motivasi yang dikembangkan oleh Maslow pada intinya berkisar pada pendapat bahwa manusia memiliki lima tingkat atau hirarki kebutuhan yang meliputi: 1 . Kebutuhan fisiologis (physiological needs), yaitu kebutuhan jasmani seperti makan, minum, pakaian, tempat untuk bernaung. 2. Kebutuhan rasa aman (safety needs), tidak hanya dalam arti perlindungan fisik, namun juga dari segi mental, psikologikal dan intelektual.3. Kebutuhan kebutuhan sosial (social needs) termasuk kebutuhan bergaul, berteman, diakui dan diterima dalam suatu kelompok / masyarakat. 4. Kebutuhan akan harga diri (esteem needs) yaitu kebutuhan untuk menghargai diri sendiri dan dihargai orang lain, terutama sehubungan dengan apa yang dilakukannya. 5. Aktualisasi diri (self actualization) dalam arti kebutuhan untuk mendapatkan kepuasan diri dengan mengembangkan potensi kemampuan dan bakat yang dimiliki secara maksimal.

Mc Intosh dan Goeldner (1995) mengemukakan bahwa motivasi wisatawan dapat dikelompokkan menjadi empat, yaitu: 1 . Motivasi fisik, adalah motivasi yang dilakukan untuk tujuan kesehatan, penyegaran tubuh, olah raga, dan menikmati waktu senggang dengan tujuan untuk mengurangi tekanan pada aktivitas rutin. 2. Motivasi Budaya, adalah motivasi yang dilakukan dengan tujuan ingin mengetahui kebudayaan dari suatu daerah, seperti cara hidup, musik, kesenian, tari-tarian, dan hal-hal yang unik dan asli dari suatu kebudayaan. 3. Motivasi Interpersonal adalah motivasi seperti melihat teman, kerabat maupun pencerahan rohani. 4. Status atau prestise, adalah motivasi yang dilakukan untuk pendidikan, ilmu pengetahuan, mendapat pengakuan atau perhatian orang lain. 
Menurut Backman, dkk (1999) dalam Esikchaikul (2012) terdapat perbedaan dan persamaan antara orang-orang yang lebih muda dibandingkan dengan yang lebih tua. Orang yang lebih muda (55-64 tahun) tertarik karena memiliki tujuan untuk relaksasi dan mengisi aktivitas di waktu luang. Sementara itu orang yang lebih tua ( $>65$ tahun) lebih karena memiliki tujuan edukasi ataupun menikmati alam.

\section{METODOLOGI PENELITIAN}

Penelitian ini dilakukan 4 (empat) obyek daya tarik wisata yang dianggap mewakili image daya tarik wisata Kota Yogyakarta yakni Kebun Binatang Gembira Loka, Taman Pintar, Benteng Vredeburg dan Kompleks Kraton. Taman sari tidak dipilih menjadi lokasi penelitian karena tidak ditemukan wisatawan lansia domestik selama penelitian. Pengumpulan data dilakukan sejak tanggal 23 Juni sampai dengan 29 Juli 2016.

Penelitian ini menggunakan teknik observasi dan wawancara mendalam (in-depth interview). Informan adalah 15 wisatawan lanjut usia domestik (usia 55 tahun keatas) yang sedang berwisata di obyek terpilih dengan teknik purposive random sampling, berdasarkan tingkat keperluan dan ketercapaian informasi yang diperlukan untuk menjawab pokok permasalahan dan tujuan penelitian iniObservasi dilakukan dengan mengamati secara langsung aktivitas wisatawan lanjut usia di lokasi penelitian. Informasi yang tidak didapatkan melalui informasi digali dengan menggunakan wawancara mendalam. Penelitian ini juga menggunakan data sekunder yang bersumber dari buku, media massa, jurnal, penelitian dan internet.

Metode analisis data dilakukan dengan cara pendekatan deskriptif-kualitatif. Data hasil wawancara, observasi, dan dokumentasi dianalisis dengan cara mengorganisasikan data ke dalam kategori, menjabarkan dalam unit-unit, melakukan sintesa, menyusun kedalam pola, memilih makna yang penting dan membuat kesimpulan sehingga mudah difahami oleh diri sendiri maupun orang lain.

\section{HASIL DAN PEMBAHASAN}

\section{Karakteristik Obyek Daya Tarik Wisata}

Daya tarik yang menjadi kajian dalam penelitian ini berkaitan dengan sesuatu yang dimiliki oleh obyek tersebut yang dianggap menarik bagi wisatawan kelompok lansia, seperti yang disajikan dalam Tabel 1 berikut:

Tabel 1. Karakteristik Obyek Daya Tarik Wisata

\begin{tabular}{|c|c|c|c|c|c|}
\hline No & Variabel & Gembira Loka & Taman Pintar & Benteng Vredeburg & Kompleks Kraton \\
\hline 1 & Lansekap & $\mathrm{V}$ & $\mathrm{V}$ & & \\
\hline 2 & Bangunan & & V & V & V \\
\hline 3 & $\begin{array}{l}\text { Daya tarik utama } \\
\text { yang ditawarkan }\end{array}$ & $\begin{array}{l}\text { Berbagai macam spesies } \\
\text { binatang yang tidak hanya } \\
\text { berasal dari Indonesia, } \\
\text { melainkan juga dari luar } \\
\text { Indonesia. }\end{array}$ & $\begin{array}{l}\text { Lokasi edukasi } \\
\text { menarik dan tidak } \\
\text { monoton y a n g } \\
\text { diperuntukan bagi } \\
\text { anak-anak. }\end{array}$ & $\begin{array}{l}\text { Bangunan yang bernilai } \\
\text { historis dengan lokasi } \\
\text { strategis. Selain itu } \\
\text { dilengkapi pula dengan } \\
\text { koleksi foto, lukisan dan } \\
\text { berbagai diorama. }\end{array}$ & $\begin{array}{l}\text { Istana Kesultanan Yogyakarta } \\
\text { yang memiliki kekayaan } \\
\text { budaya yang menonjol berupa } \\
\text { bangunan unik khas Jawa. }\end{array}$ \\
\hline \multirow[t]{9}{*}{4} & \multicolumn{5}{|c|}{ Fasilitas untuk difabel } \\
\hline & Toilet & $\mathrm{V}$ & $\mathrm{V}$ & & \\
\hline & Ramp & V & V & V & \\
\hline & Jalur kursi roda & V & $\mathrm{V}$ & & \\
\hline & Kursi roda & V & V & $\mathrm{V}$ & V \\
\hline & Tempat duduk & V & $\mathrm{V}$ & V & \\
\hline & \begin{tabular}{|l|} 
Kanopi \\
(perindang)
\end{tabular} & V & $\mathrm{V}$ & V & \\
\hline & Signage (rambu) & V & V & V & \\
\hline & Petugas & V & V & V & V \\
\hline
\end{tabular}

Sumber: Olahan data primer (2016)

\begin{tabular}{l|l} 
JNP & ${ }_{86}$
\end{tabular} 
Banyak wisatawan lansia yang menganggap bahwa bangunan dan lansekap obyek tersebut yang menjadi elemen paling menarik. Susunan lansekap kebun binatang gembiraloka menjadi daya tarik karena terdiri dari lahan yang luas dengan ketinggian yang bervariasi. Susunan vegetasi dengan kombinasi pohon besar peneduh dan tanaman perdu maupun tanaman bunga dianggap menarik untuk aktivitas berjalan maupun duduk-duduk. Obyek wisata Kraton dan Benteng Vredeburg dianggap lebih menarik dari segi bangunan yang bernilai historis. Dari ketiga obyek wisata tersebut, daya tarik kraton dan benteng Vredeburg dianggap tinggi bagi wisatawan lansia karena selain memiliki bangunan yang bernilai historis tinggi, tempat tersebut juga dilengkapi dengan koleksi museum beserta informasi tertulis. Wisatawan lansia tidak hanya sekedar dapat menikmati bangunan maupun koleksi benda-benda bersejarah tetapi sekaligus mendapatkan cerita atau informasi tentang koleksi tersebut. Hal ini diangggap penting karena lansia dapat menikmati ODTW tersebut bersama-sama dengan cucu maupun anggota keluarga yang lain sambil bercerita kepada mereka. Misalnya tentang kondisi jaman dulu dibandingkan dengan kondisi jaman sekarang, atau yang berkaitan dengan pengalaman mereka waktu muda. Sedangkan fasilitas bagi kaum difabel (different ability) meskipun bermanfaat bagi wisatawan lansia, namun tidak dianggap menjadi hal yang penting selama mereka berwisata bersama-sama dengan keluarga atau kelompok.

\section{Karakteristik Wisatawan Lanjut Usia}

Wisatawan lanjut usia yang mengunjungi 4 (empat) ODTW utama di Yogyakarta memiliki karakteristik yang tidak jauh berbeda dengan wisatawan domestik pada umumnya. Karakteristik wisatawan lansia dalam Tabel 1 dikelompokkan menurut golongan umur lansia, jenis kelamin dan keterbatasan fisik mereka. Mayoritas Wisatawan lansia yang mengunjungi ODTW masuk dalam kelompok usia 60-65 tahun, diikuti dengan kelompok usia di atas 65 tahun dan usia 55-59 tahun. Dari aspek jenis kelamin, baik lansia laki-laki maupun perempuan samasama melakukan kegiatan wisata di ODTW. Lansia umur 60-65 tahun tergolong dalam kelompok lansia menengah yang dicirikan dengan kemampuan fisik yang mulai menurun tetapi masih dapat melakukan perjalanan maupun aktivitas fisik yang terbatas. Secara umum, lansia yang mengunjungi keempat lokasi penelitian tersebut tidak memiliki kekurangan fisik yang berpotensi menghalangi lansia dalam berwisata, misalnya kecacatan fisik. Dari hasil wawancara dan observasi lapangan, lansia lebih memilih untuk duduk di tempat yang teduh atau berjalan di tempat yang landai. Mereka menghindari aktivitas fisik yang membutuhkan tenaga lebih seperti naik tangga, berdiri, berjalan atau terpapar sinar matahari dan suhu panas. Aktivitas fisik seperti berdiri dan berjalan masih dilakukan oleh lansia meskipun dengan intensitas yang rendah. Hal ini menunjukkan bahwa lansia memiliki keterbatasan ruang gerak dan penurunan kekuatan dalam melakukan aktivitas fisik.

Tabel 2. Karakteristik Wisatawan Kelompok Lansia

\begin{tabular}{|c|l|l|l|l|l|l|}
\hline No & \multicolumn{1}{|c|}{ Variabel } & $\begin{array}{c}\text { Gembira } \\
\text { Loka }\end{array}$ & $\begin{array}{c}\text { Taman } \\
\text { Pintar }\end{array}$ & $\begin{array}{c}\text { Benteng } \\
\text { Vredeburg }\end{array}$ & $\begin{array}{c}\text { Kompleks } \\
\text { Kraton }\end{array}$ & \multicolumn{1}{|c|}{ Keterangan } \\
\hline \multirow{4}{*}{1} & Golongan lansia & & V & & V & Usia perkiraan, dari hasil interview \& observasi \\
\cline { 2 - 6 } & $55-59$ tahun & V & V & V & V & \\
\cline { 2 - 6 } & $60-65$ tahun & V & & V & V & \\
\cline { 2 - 4 } & $>65$ tahun & &
\end{tabular}




\begin{tabular}{|c|c|c|c|c|c|c|}
\hline \multirow[t]{3}{*}{2} & \multicolumn{6}{|l|}{ Jenis kelamin } \\
\hline & Laki-laki & $\mathrm{V}$ & $\mathrm{V}$ & $\mathrm{V}$ & $\mathrm{V}$ & \multirow[t]{2}{*}{ Laki-laki \& perempuan ditemukan di ODTW } \\
\hline & Perempuan & V & $\mathrm{V}$ & V & $\mathrm{V}$ & \\
\hline 3 & Keterbatasan fisik & $\mathrm{V}$ & V & V & & Berjalan pelan, mudah letih, kepanasan \\
\hline \multirow[t]{9}{*}{4} & \multicolumn{6}{|l|}{ Aktivitas } \\
\hline & Duduk & $\mathrm{V}$ & V & V & & \\
\hline & Jalan & V & V & V & $\mathrm{V}$ & \\
\hline & Ngobrol & $\mathrm{V}$ & V & V & $\mathrm{V}$ & \\
\hline & Makan & V & V & & & \\
\hline & Membaca & $\mathrm{V}$ & & V & & \\
\hline & Mengasuh cucu & $\mathrm{V}$ & $\mathrm{V}$ & & & \\
\hline & Foto & V & & V & $\mathrm{V}$ & \\
\hline & Melihat-lihat & V & V & V & V & \\
\hline
\end{tabular}

Sumber: Olahan data primer (2016)

Wisatawan lansia lebih banyak melakukan kegiatan wisata pasif (passive activities) yakni duduk, membaca, melihat-lihat, makan dan ngobrol. Sementara kegiatan aktif yang dilakukan oleh wisatawan lansia adalah jalan, mengambil foto dan mengasuh cucu. Aktivitas pasif dan aktif yang dilakukan wisatawan tersebut juga ditentukan oleh ada atau tidaknya fasilitas yang mendukung di obyek wisata yang dikunjungi. Wisatawan lansia di Kebun Binatang Gembira Loka bisa melakukan banyak aktivitas, baik pasif maupun aktif, karena didukung oleh fasilitas yang ada di obyek tersebut. Sebaliknya, sedikit aktivitas yang bisa dilakukan oleh wisatawan lansia di Kompleks Kraton, karena obyeknya yang tidak terlalu luas dan sedikit fasilitas yang disediakan di obyek tersebut. Baik kegiatan pasif maupun aktif yang dilakukan oleh wisatawan lansia dapat digolongkan dalam kegiatan untuk mendukung interaksi sosial dengan kegiatan yang membangkitkan nostalgia mereka, melakukan interaksi sosial dengan anggota keluarga maupun sesama kaum lanjut usia.

\section{Motivasi Wisatawan Lanjut Usia dalam Melakukan Aktivitas Berwisata}

Motivasi berwisata berhubungan dengan alasan mengapa manusia melakukan kegiatan wisata. Hasil wawancara dengan lansia di obyek wisata menyebutkan ada 4 (empat) motivasi yang mendorong wisatawan lansia mengunjungi obyek wisata tersebut. Jenis motivasi tersebut dapat dilihat pada tabel berikut:

Tabel 3. Motivasi Lansia untuk Berwisata

\begin{tabular}{|l|l|l|l|l|l|}
\hline No & Variabel & $\begin{array}{l}\text { Gembira } \\
\text { Loka }\end{array}$ & $\begin{array}{l}\text { Taman } \\
\text { Pintar }\end{array}$ & $\begin{array}{l}\text { Benteng } \\
\text { Vredeburg }\end{array}$ & $\begin{array}{l}\text { Kompleks } \\
\text { Kraton }\end{array}$ \\
\hline 1 & $\begin{array}{l}\text { Wisata } \\
\text { bersama } \\
\text { keluarga }\end{array}$ & V & V & V & V \\
\hline 2 & Nostalgia & V & & & V \\
\hline 3 & Mengisi waktu & & V & & \\
\hline 4 & $\begin{array}{l}\text { Ikut kegiatan } \\
\text { kolektif }\end{array}$ & V & & V & \\
\hline
\end{tabular}

Sumber: Olahan data primer (2016)

Keinginan berwisata kaum lanjut usia berbeda dengan wisatawan pada umumnya. Keinginan berwisata mereka lebih didorong dengan keinginan untuk berkumpul bersama orang lain, baik bersama keluarga maupun teman-teman komunitas. Individu lanjut usia melakukan kegiatan wisata apabila diajak oleh anggota keluarga atau diajak oleh komunitas, sehingga mereka mengikuti preferensi dari anggota keluarga atau komunitas. Motivasi dasar seperti itu menyebabkan keinginan untuk berwisata lebih didorong oleh faktor eksternal atau dorongan dari luar, dalam hal ini adalah 
dorongan dari lingkungan keluarga atau lingkungan komunitas yang mendukung untuk berwisata secara kolektif. Hasil interview terkait motivasi internal atau motivasi yang berasal dari dalam diri sendiri, yang mendorong individu lansia untuk berwisata menunjukkan keinginan lansia tersebut untuk bersosialisasi dengan anggota keluarga ataupun dengan anggota komunitas.

Motivasi yang kedua berhubungan dengan banyaknya waktu luang yang dimiliki oleh lansia, sehingga berwisata adalah salah satu cara untuk mengisi waktu luang bersama dengan orang lain sambil berjalan-jalan menikmati lingkungan yang berbeda. Selain kedua motivasi utama tersebut, lansia membuat pilihan untuk mengunjungi obyek wisata kebun binatang gembiraloka atau kraton karena ada keterkaitan emosi atau nostalgia masa lalu dengan ODTW tersebut. Dua ODTW tersebut termasuk ODTW yang sudah lama berdiri, sehingga sebagian besar lansia pernah mengunjungi obyek tersebut ketika mereka masih muda atau ketika anak-anak mereka belum berusia dewasa. Dihubungkan dengan teori Mc.Intosh tentang motivasi berwisata, motivasi yang mendorong lansia untuk berwisata lebih kepada motivasi sosial, impersonal, dan motivasi fisik.

Motivasi seperti ini bila dihubungkan dengan pengertian berwisata, yakni kegiatan di luar lingkungan sehari-hari, menunjukkan bahwa lansia tersebut dikatakan berwisata karena mereka keluar dari lingkungan hidup mereka sehari-hari dalam hal ini adalah lingkungan tempat tinggal mereka. Yang berbeda adalah pilihan untuk berwisata tidak hanya dipengaruhi oleh motivasi internal tetapi lebih didorong oleh motivasi eksternal atau dorongan dari luar.

\section{KESIMPULAN DAN SARAN}

\section{Kesimpulan}

- Karakteristik wisatawan lansia menunjukkan bahwa kelompok lanjut usia yang mengunjungi ODTW yang menjadi lokasi penelitian sebagian besar berusia 60-65 tahun diikuti kelompok usia diatas 65 tahun dan usia 55-65 tahun. Lansia 60-65 tahun tergolong dalam kelompok lansia menengah, dengan ciri-ciri kemampuan fisik yang mulai menurun tetapi masih bisa melakukan perjalanan dan aktivitas fisik terbatas.

- Wisatawan lansia lebih banyak melakukan kegiatan wisata pasif (passive activities) yakni duduk, membaca, melihat-lihat, makan dan ngobrol. Sementara kegiatan aktif yang dilakukan oleh wisatawan lansia adalah jalan, mengambil foto dan mengasuh cucu. Aktivitas pasif dan aktif yang dilakukan wisatawan tersebut juga ditentukan oleh ada atau tidaknya fasilitas yang mendukung di obyek wisata yang dikunjungi.

- Keinginan berwisata kaum lanjut usia berbeda dengan wisatawan pada umumnya. Keinginan berwisata mereka lebih didorong dengan keinginan untuk berkumpul bersama orang lain, baik bersama keluarga maupun teman-teman komunitas. Motivasi yang mendorong lansia untuk berwisata lebih kepada motivasi sosial, impersonal, dan motivasi fisik.

\section{Saran}

Wisatawan lansia memiliki kebutuhan ruang yang berbeda dengan wisatawan pada umumnya. Kebutuhan ruang bagi wisatawan lansia tersebut berhubungan dengan kemampuan fisik mereka yang mengalami penurunan. Sehingga penyediaan fasilitas dan ruang untuk memenuhi kebutuhan wisatawan lansia perlu disesuaikan dengan dua hal penting. Yang pertama berkaitan dengan karakter wisatawan lansia yang berhubungan dengan kemampuan fisik mereka, sedangkan yang kedua berhubungan dengan motivasi lansia dalam melakukan kegiatan wisata.

Indikator kemampuan merujuk pada Individu lanjut usia yang memiliki kepekaan yang tinggi terhadap perubahan suhu dan 
cuaca, dari suhu yang dingin menjadi panas atau sebaliknya. Implikasinya, destinasi wisata perlu menyediakan peneduh (shelter) dan rekayasa suhu dengan menggunakan elemen alami vegetasi maupun elemen buatan. Wisatawan lansia yang banyak melakukan aktivitas pasif membutuhkan tempat untuk beristirahat seperti tempat duduk sambil menikmati pemandangan dan jalur pedestrian yang landai. Fasilitas keruangan untuk memenuhi kebutuhan wisatawan lansia juga harus disesuaikan dengan karakter dari masing-masing destinasi wisata agar memiliki kekhasan. Fasilitasfasilitas tersebut selain diperuntukkan bagi wisatawan lanjut usia juga dapat dimanfaatkan oleh wisatawan lain atau wisatawan difabel yang memiliki keterbatasan atau perbedaan kemampuan fisik dengan wisatawan pada umumnya.

Berkaitan dengan motivasi utama dalam berwisata, yakni motivasi fisik, sosial dan impersonal, atraksi daya tarik yang sangat potensial untuk dikembangkan bagi wisatawan lansia adalah wisata sejarah, wisata budaya, wisata alam dan wisata keluarga yang bisa dilakukan oleh wisatawan lansia secara berkelompok bersama keluarga maupun komunitasnya.

\section{DAFTAR PUSTAKA}

Badan Kependudukan dan Keluarga Berencana Nasional (BKKBN) Jakarta. 2014. Pedoman Pembinaan Ketahanan Keluarga Lansia.

Cooper, C \& Wahab, S (eds.). 2005. Tourism in the Age of Globalisation. London: Routledge

Esichaikul, R., 2012. Travel Motivations, Behavior and Requirements of European Senior Tourists to Thailand. PASOS 10(2).Special Issue. 2012, 10, pp.47-58.

Hall, Michael C. \& Page, Hall. 2002. The Geography of Tourism and Recreation: Environment, Place and Space. London: Routledge.
Hsu, C.H.C., Cai, L.A. \& Wong, K.K.F., 2007. A Model of Senior Tourism MotivationsAnecdotes from Beijing and Shanghai. Tourism Management (28), pp.1262-1273.

Kependudukan DIY. 2016. Jumlah Penduduk DIY Menurut Kelompok Umur Per-5 Tahun. Periode semester II Tahun 20142016. http://kependudukan.jogjaprov. go.id/olah.php?module=statistik. Diakses pada tg1 23 Februari 2017 jam 11:46.

McIntosh, R.W., Goeldner, C.R. and Ritchie, J.R.B. 1995. Pleasure Travel Motivation. Tourism: Principles, Practices, Philosophies., (Ed. 7), pp.167-190.

Peraturan Menteri Kesehatan Republik Indonesia Nomor 25 Tahun 2016 Tentang Rencana Aksi Nasional Kesehatan Lanjut Usia Tahun 2016-2019.

Pusat Data dan Informasi Kementrian Kesehatan Republik Indonesia. 2016. InfoDATIN Situasi Lanjut Usia (Lansia) Di Indonesia.

Pusat Data dan Informasi Kementrian Kesehatan RI (2014). Situasi dan Analisis Lanjut Usia.

Shawn, S. \& Wu, C.E. 2006. Seniors' Travel Motivation and the Influential Factors : An Examination of Taiwanese Seniors. Tourism Management (27), pp.306-316.

Srichuae, S., Nitivattananon, V. \& Perera, R. 2016. Aging Society in Bangkok and the Factors Affecting Mobility of Elderly in UrbanPublic Spaces and Transportation Facilities. IATSSR, 40(1), pp.26-34. Tersedia di : http://dx.doi.org/10.1016/j. iatssr.2015.12.004.

Undang-Undang Republik Indonesia Nomor 13 tahun 1998 tentang Kesejahteraan Lansia.

WHO. 2007. Global Age Friendly Cities: A Guide. Prancis: WHO Press. 